Personalidade Acadêmica Homenageada:

Raymundo Juliano Feitosa (Universidade Federal do Rio Grande do Norte - UFRN)

\title{
O PACTO GLOBAL E A IGUALDADE RACIAL NO AMBIENTE DE TRABALHO
}

\section{THE GLOBAL COMPACT AND RACIAL EQUALITY IN THE WORKPLACE}

\section{LUCIANE MARIA TRIPPIA}

Doutoranda pelo Programa de Pós-Graduação em Tecnologia e Sociedade (PPGTE), da Universidade Tecnológica Federal do Paraná (UTFPR). Professora licenciada do Centro Universitário Curitiba - UNICURITIBA. Bolsista CAPES. Curitiba - PR. E-mail: lutrippia@terra.com.br

\section{NANCI STANCKI DA LUZ}

Doutora em Política Científica e Tecnológica pela Universidade Estadual de Campinas (UNICAMP). Professora no Programa de Pós-Graduação em Tecnologia e Sociedade (PPGTE), da Universidade Tecnológica Federal do Paraná (UTFPR). Curitiba - PR. E-mail: nancist@terra.com.br

\section{RESUMO}

A história dos direitos humanos demonstra que esses direitos são frutos de desafios que surgem com a evolução da sociedade. O direito a igualdade racial, reconhecido internacionalmente enquanto direito humano, incide também no campo trabalhista, onde é comum a ocorrências de práticas discriminatórias. Pesquisas diversas confirmam uma condição desigual da população negra no Brasil, inclusive no 


\section{Personalidade Acadêmica Homenageada:}

Raymundo Juliano Feitosa (Universidade Federal do Rio Grande do Norte - UFRN)

ambiente de trabalho, como reflexo de uma violência real e simbólica, notadamente em relação à mulher negra. De outro lado, com o fenômeno da globalização e seus impactos sobre os direitos humanos, diversos tipos de organizações, para além dos poderes públicos, são considerados agentes importantes com condições para desempenhar um papel fundamental nesta defesa, como o setor privado, academia, comunidade jurídica e sociedade civil. E é nesta perspectiva que se insere o Pacto Global das Nações Unidas, que consiste, basicamente, em um compromisso que instituições diversas assumem, voluntariamente, para observarem em suas práticas cotidianas a implementação de dez princípios universalmente aceitos relacionados a quatro áreas, a saber: direitos humanos, trabalho, meio ambiente e combate à corrupção. À luz de dois dos princípios do Pacto Global, que versam sobre a questão dos direitos humanos, as instituições participantes assumem o compromisso de respeitá-los. Por isto, na presente pesquisa, pretende-se investigar em que medida instituições signatárias do Pacto Global, especialmente relacionadas à comunidade jurídica do Brasil, prevêem mecanismos para a promoção do direito à igualdade racial, enquanto um direito humano reconhecido, inclusive, pelo ordenamento jurídico brasileiro. Para tanto, está sendo realizada pesquisa no portal eletrônico do Pacto Global, junto ao diretório de relatórios "Comunicação de Engajamento Communication on Engagement" (COE) de instituições da área jurídica no país. Os resultados preliminares indicam primeiramente que, em razão da falta de um padrão oficial para a realização da informação pelas instituições, pode ensejar algum prejuízo na análise das ações que estas vêm fazendo em prol da promoção da igualdade racial. Todavia, da análise realizada até o momento, pode-se verificar algumas ações de escritórios de advocacia neste sentido. Contudo, há que se dar prosseguimento ainda neste trabalho, a fim de verificar como e o quanto a comunidade jurídica brasileira, signatária do Pacto Global, está comprometida com a promoção dos direitos humanos da população negra, em uma sociedade que se pretende justa e igualitária. 
Personalidade Acadêmica Homenageada:

Raymundo Juliano Feitosa (Universidade Federal do Rio Grande do Norte - UFRN)

PALAVRAS-CHAVE: Pacto Global; Igualdade; Discriminação racial; Direitos Humanos.

\section{REFERÊNCIAS}

BAUMAN, Zygmunt. Globalização: as consequências humanas. Tradução Marcus Penchel. Rio de Janeiro: Zahar, 1999.

BOBBIO, Norberto. A era dos direitos. Rio de Janeiro: Elsevier, 2004. BONAVIDES, Paulo. Curso de direito constitucional. 25 ed. São Paulo: Malheiros, 2010.

LAFER, Celso. A reconstrução dos direitos humanos: um diálogo com o pensamento de Hannah Arendt. São Paulo: Companhia das letras, 1988.

PIOVESAN, Flávia. Direitos humanos e o direito constitucional internacional. 7. ed. São Paulo: Saraiva, 2006.

ORGANIZAÇÃO DAS NAÇÕES UNIDAS (ONU). (1948) Declaração Universal dos Direitos Humanos. Disponível em: <http://www.dudh.org.br/wpcontent/uploads/2014/12/dudh.pdf>. Acesso em: 01 jun. 2019.

ORGANIZAÇÃO DAS NAÇÕES UNIDAS (ONU). (1966) Pacto Internacional dos Direitos Civis e Políticos. Disponível em: <http://www.planalto.gov.br/ccivil_03/decreto/1990-1994/d0592.htm>. Acesso em: 01 jun. 2019.

PACTO GLOBAL. Disponível em: < https://www.pactoglobal.org.br/>. Acesso em 01 jun 2019.

SILVEIRA, Vladimir Oliveira; SANCHES, Samyra Haydee Dal Farra Naspolini. Direitos Humanos, Empresa e Desenvolvimento Sustentável. Revista Jurídica Unicuritiba. ISSN: 2316-753X. Disponível em: < http://revista.unicuritiba.edu.br/index.php/RevJur/article/view/1422>. Acesso em 01 jun. 2019. 